The Journal of International Lingual, Social and Educational Sciences Year: 2019, Volume: 5, Number: 1

DOI: $10.34137 /$ jilses.477947

Geliş Tarihi: 02.11.2018

Kabul Tarihi: 04.02.2019

Makale Türü: Araştırma Makalesi
Received: 02.11 .2018

Accepted: 04.02.2019

Research Type: Research Article

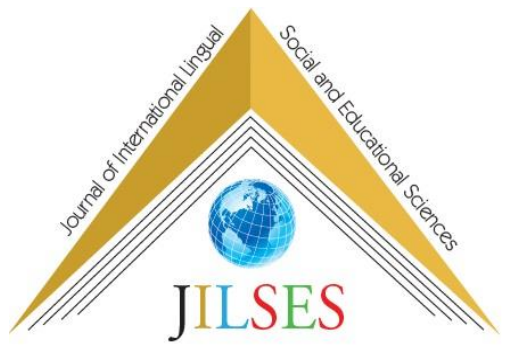

\title{
Doğal Boyamanın Farklı Tekstil Lifleri İle Oluşturulan Yüzeylere Etkisi
}

\author{
Esra Sunerli ${ }^{1}$, Muazzez Çakır Aydın ${ }^{2}$
}

$\ddot{O z e t}$

Binlerce ylldır doğal boyama, kumaş yüzeylerini süslemede ve sembolik açıdan anlamlandırmada kullanılmaktadır. Kullanılan bu boyar maddelerin öncelikli olarak bitki, böcek ve hayvansal renklendiricilerden elde edildiği bilinmektedir. Boyama ile ilgili ilk kanıt Hindistan'da yapılan kazılarda M.Ö. 3000 ylllarına ait bitkisel pigment ile boyanmış bir pamuk parçasınin keşfedilmesine dayanır. Önemli ve zengin kişilerin doğal boyalar ile boyanmış giysiler giydiği bilinmektedir. Roma imparatorları da kendini görsel olarak diğer insanlardan ayırmak için bu şekilde renklendirilerek süslenmiş giysiler giymişlerdir. 19.yy'a kadar doğal boyama oldukça sik kullanılan bir yöntem olmasina rağmen Endüstri Devrimi ve kimyasal boyanın icadı ile birlikte kumaş yüzeyleri daha teknolojik fakat doğaya zararl etkiler bırakan yöntemlerle renklendirilmeye başlanmişstır. Günümüzde bu kimyasal boyar maddeler çeşitli çevre örgütlerinin üstünde durduğu bir konu haline gelmişstir. Bu çalışmada doğal boyar maddeler kullanılarak pamuklu, sentetik, yünlü tekstil yüzeylerinde ve hayvan derisi üzerindeki renklendirme etkisi incelenecek, ekolojik boyama yöntemlerinden bahsedilecektir. Boyanacak tekstil yüzeylerinin her birine eşit miktarda aynı doğal renklendirici uygulanarak sonuçlar görselleri ile birlikte sunulacaktır.

Anahtar Kelimeler: Doğal Boyama, Ekolojik Boyama, Tekstil, Moda Tasarım, Sürdürülebilirlik.

\section{Effect of Natural Dyeing on Surfaces Formed with Different Textile Fibers}

\begin{abstract}
For thousands of years, natural dyeing has been used to decorate fabric surfaces and to make sense of symbolic meaning. These dyestuffs are known to be derived primarily from plant, insect and animal colorants. The first evidence of natural dyeing is based on the discovery of a cotton piece stained with vegetable pigment from BC3000 during the excavations in India. It is known that important and rich people wear clothes dyed with natural dyes. The Roman emperors also dressed in this way to make their clothes visually differentiated from other people. Although natural painting was a very common method until the 19th century, the fabric surfaces were colored with the invention of the Industrial Revolution and chemical paint. Nowadays, these chemical dyestuffs have become the subject of various environmental organizations. In this study, the coloration effect on cotton, synthetic, woollen textile surfaces and animal skin was investigated by using natural dyestuffs and ecological dyeing methods were mentioned. The same natural colorant is applied to each of the textile surfaces to be painted with the same visuals.
\end{abstract}

Keywords: Natural Dyeing, Ecological Dyeing, Textile, Fashion Design, Sustainability.

\footnotetext{
1 Öğr. Gör, Uşak Üniversitesi, Türkiye, esra.sunerli@ usak.edu.tr, http://orcid.org/0000-0002-6620-3105

2 Öğr. Gör, Uşak Üniversitesi, Türkiye, muazzez.aydin@usak.edu.tr
} 


\section{Giriş}

İnsanlık tarihine bakıldığında sanatın ortaya çıkışını tam olarak kestiremediğimiz gibi boyamacılık tarihinin başlangıcını da kestiremiyoruz. Doğal boyalar, yıllar boyunca çeşitli bitkiler, hayvanlar ve minerallerden elde edilmişlerdir. Doğal boyalar antik çağlardan beri yün, ipek, deri pamuk gibi çeşitli doğal liflerin renklendirilmesinde yaygın olarak kullanılmaktadır (Bechtold, Mussak, 2009, s. 3-17). Doğal boyama maddeleri; Cilalı Taş Devri'nden kalma barınak yapılarda rastlanan ve av sahnelerini konu alan duvar resimlerinden, dokumalarının hammaddeleri olan yün, tiftik, pamuk ve ipeğe renk verilmesine kadar insan yaşamının ve sanatın bir parçası olduğu söylenebilir. Tekstil boyamacılı̆̆ı ile ilgili ilk kanıt Hindistan'da yapılan kazılarda M.Ö. 3000 yıllarına ait bitkisel pigment ile boyanmış bir pamuk parçasının keşfedilmesine dayanır (Bhardwaj; Jain, 1982, s.70). Bilinen en eski boyar maddelerden birisi indigo maddesidir. İndigo boyar maddesinin, M.Ö.3500 y1llarında o zaman Hindistan sınırları içinde olan bir arkeolojik yerleşim yerinde bulunmasından dolayı ilk kullanıldığ yerin Hindistan olduğu varsayılabilir (Karadăg, 2007, s.8).

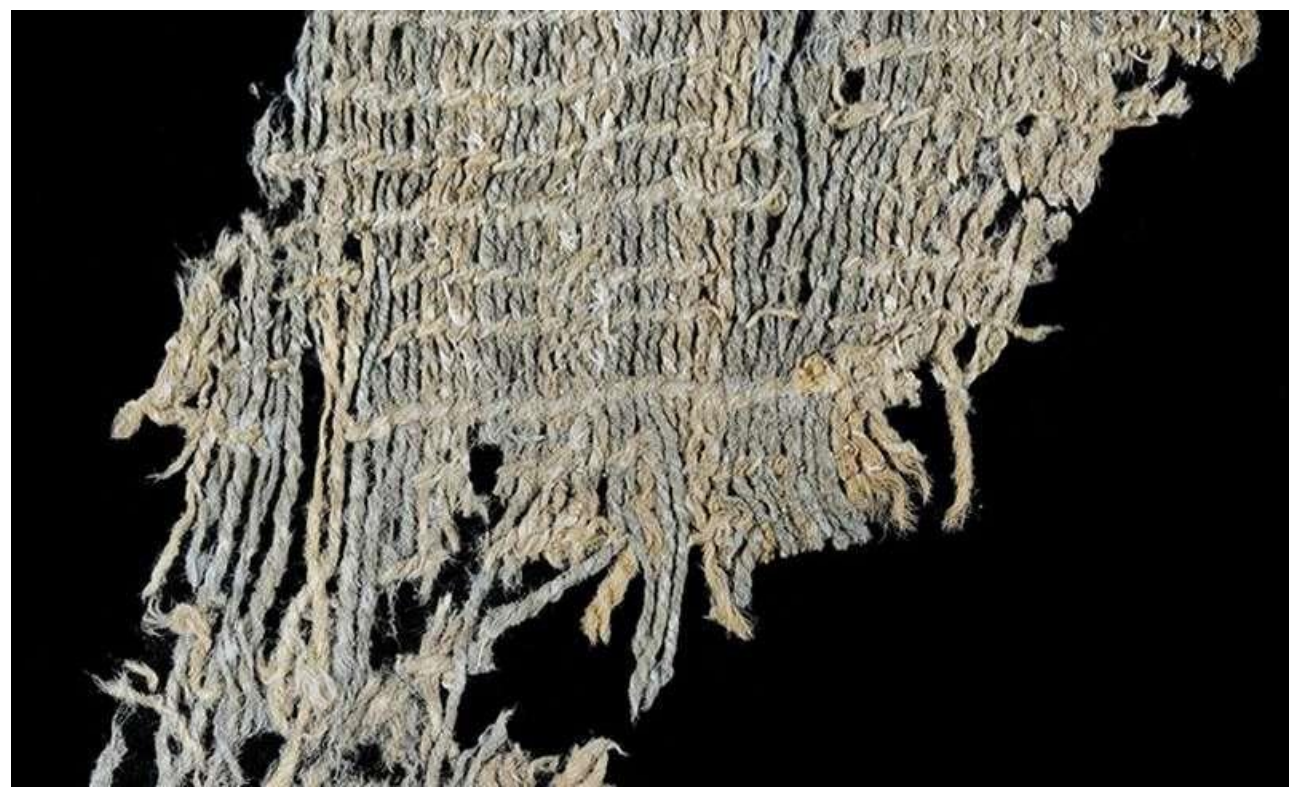

Görüntü 1: Indigo mavisi ile renklendirilmiş Peru'da bulunan 6200 ylllk bilinen eski dokumalarından bir örnek Kaynak: https://phys.org/news/2016-09-oldest-textile-dyed-indigo-blue.html

Bazı bitkiler, böcekler ve deniz kabuklularından çeşitli renklerde doğal boyar maddeler elde edilebilmektedir. Bitkilerin kök, gövde, yaprak, çiçek ve meyvelerinin boyarmadde ve pigment olarak kullanımı insanlık tarihi kadar eskidir. Boya bitkilerinin kullanımının MÖ. 4000 yıllarına kadar gittiği söylenmektedir. Ancak endüstrileșmenin akabinde sentetik boyarmaddelerin keşfedilmesi ile boya bitkilerinin kullanımı azalarak ortadan kalkma noktasına gelmiştir. 1980'li yıllarda sentetik boyarmaddelerin birçoğunun toksik, kanserojen ve çevre kirliliğine neden olduğunun tespit edilmesi ile birlikte doğal boyamacılık yeniden önem kazanmıştır. Bunun sonucu olarak sürdürülebilirlik kavramı hayatımıza girmiştir. Doğal bitki örtüsü bakımından dünyanın en zengin topraklarına sahip olan Türkiye, aynı zamanda boya bitkileri bakımından da dünyanın en zengin ülkesidir. Bu nedenle gerek Selçuklu gerekse Osmanlı İmparatorluğu bu zengin boya bitkilerini tekstilin her alanında kullanmıştır. Türkler bu nedenle boyamacılık alanında dünyada önemli bir yere sahip olmuş ve "Türk Kırmızısı" adıyla ün kazanmıştır. Bütün dünyada kullanılan boya bitkilerin sayısı 300 ile 400 arasında olduğu varsayılmaktadır. Türkiye'de ise boya bitki sayısının yaklaşı 250 civarında olduğu bilinmektedir. Dünyadaki altı adet boya böceğinin üç adedi Türkiye'de yetişmektedir. Boyama için kullanılan deniz kabukluları Marmara Denizi, Ege Denizi, Akdeniz ve Karadeniz'de bulunmaktadır. Özellikle tarım, gıda, ilaç, orman yiyecek işletmelerinden çıkan atıklar da doğal boya olarak yeniden değerlendirilebilmektedir (Yıldırım, İşmal, 2017 s.132). Kullanılan doğal boyarmaddeler çevre kirliliğine yol açmayan, toksik ve kanserojen olmayan aynı zamanda da doğal antibakteriyel ve antimikrobiyal özellikler göstermektedir (http://www.tcfdatu.org/tr/servisler/servisler/dogal-boyama-31.htm).

\section{Yöntem}

Bu çalışmada; çevreci bir düşünce yapısı 1şı̆̆ında bitkisel boyama yöntemlerini farklı tekstil lifleri ile oluşturulmuş yüzeylerdeki etkileri ve sonuçlarının değerlendirilmesi yapılmıştır. Günümüzde artan çevre bilinci sayesinde sentetik boyaların sebep oldukları çevre kirlilikleri, insan sağlığına zarar veren toksik etkileri ve atık problemleri nedeniyle sentetik boyaların kullanımına yönelik bir karşı duruş oluşmuştur. Sentetik boyalara karşı gelişen 
farkındalık bilinciyle beraber yenilenebilir, minimum çevre kirliliğine sebep olan ve genellikle insan sağlığına zararlı etkisi olmayan doğal boyaların kullanımına yönelik artan bir ilgi de gözlenmektedir. Doğal boya pazarı giderek artan şekilde büyüyen ve talep gören bir sektör haline gelmektedir. Doğal boyalara doğru artan bu ilgiyle beraber insanların çok eski zamanlardan bu yana kullandıkları doğal baskı teknikleri ile tekstil yüzeylerini renklendirme uygulaması gündeme gelmiştir (Bilir, 2018, s.64). Günümüz tüketici toplumunda, artan çevre sorunları mevcut yaşam tarzlarına, modaya, giyime ve tekstile de yansımaktadır. Tekstil ürünlerinde kullanılan kanserojen sentetik boyaların kullanımı tüketicileri ve dolayısı ile üreticileri doğal boyama yapmaya sevk etmektedir. Doğal boyar maddelerin çevreye duyarlı olması, temiz üretim yöntemlerinin tercih edilmesi ve boyama yöntemlerinin çevre dostu olması dikkat çeken unsurlardır. Doğala yönelim, ekolojik ve sürdürülebilir modaya katkıda bulunulmasını sağlamaktadır (Oyman, Can, 2017, s.190).Küresel 1sınma ve çevresel kirliliğin artması ile sürdürülebilir moda kavramı hayatımıza girmiştir. Aslında sürdürülebilir moda paradokslarla doludur. Çünkü moda, temelde sezonluk ve hızlı değişen eğilimlerle ilgilidir. Sürdürülebilirlik ise tanım olarak uzun sürmek anlamına gelmektedir. Sürdürülebilir moda ilgi çekici olmayı, moda ürünler kullanmayı, modanın hızlı olan rutinine aykırı olmayı ve tüketim çılgınlığına katılmayı reddetmek anlamına gelmektedir (Gürcüm, Yüksel, 2012, s.50). Ekolojik moda ise pamuk, keten iplikleriyle üretilmiş kıyafetler ve doğal boyalarla boyanmış kumaşları kapsamaktadir.

Boyar madde olarak nar çiçeği, Mekke gülü, hatmi çiçeği veya hibiskus (hibiscus) olarak bilinen kırmızı tonlarda pigmentlere sahip bir çiçek kullanılmıştır. Hibiskusun yapısında boyarmadde özelliği taşıyan yapılar bulunmaktadır. Yapısında bulunan ve boyarmadde özelliği gösteren madde Antosiyanidin grubuna giren Cyanidin etkin maddesidir (Benli, Yılmaz, Bahtiyari, 2012, s.23). Boyama işleminin kalıcı olabilmesi maddeler de kullanılır. Doğal liften yapılmış tekstil yüzeylerinde doğal boyarmaddelerle renklendirme işlemi yapılabilmesi için çoğunlukla mordanlama işleminin uygulanması gerekmektedir. Mordanlama işlemi boya ile tekstil yüzeyi arasındaki afiniteyi arttırır böylece daha parlak renkler, kalıcılığı daha iyi boyamalar ve daha geniş renk spektrumları elde edilebilir (Kadolph, Casselman, 2004, s15-47; Shadid vd., 2013, s. 310-311). Mordanlar; liflerin emme kabiliyetini arttıran, boyanın lifler üzerinde tutunmasını sağlayan şap, soda, sodyum sülfat, sodyum karbonat, bakır sülfat, alüminyum sülfat gibi maddelerdir. Bunlar aynı zamanda boyaların tonlarına da etki ederler (Islam, Mohammad, 2017 s.119). Eritkenler; boyaların, içlerinde eridiği maddelerdir. Özellikle suda eriyen boyalar için suyun kireçsiz ve demirsiz olması gerekir. Yardımcı madde olarak boyanın parlak ve dayanıklı olması için kullanılan asit, baz ve tuzlardır (Kırmızı, 2009, s.28).

Çalışmada yedi farklı tekstil yüzeyinin hibiskus bitkisi ile renklendirilmesi incelenmiştir. Hibiskus bitkisi, iyi haslık özelliklerine sahip tonlar verir. Bitki, pamuk, ipek ve yün ipliği ticareti kapsamında boyama işleminde de kullanılmaktadır (Shanker, Vankar, 2007,s. 464-469). Hibiskus bitkisini kullanarak farklı mordanlama yöntemleriyle ortaya çıkan sonuçları belgeleyen Hashim vd.'e göre de Hibiskus bitkisi doğal boyama işlemi için önemli bitki kaynaklarından biri olarak kullanılmaktadır (2018, s. 62). Hibiskus ile boyanacak tekstil yüzeylerinin hepsi beyaz veya saf renkte olmak üzere; bir adet bez ayağı dokuma ve bir adet dimi dokumadan oluşan pamuklu kumaş, bir adet polyester kumaş, bir adet polyester-pamuk karışımlı dimi dokuma, bir adet koyun yününün elde keçeleştirilmesiyle oluşturulan yüzey ve koyun ve dana derileri olmak üzere iki adet deri yüzey kullanılmıştır. Ayrıca her tekstil yüzeyi ayrı ayrı olmak üzere; 1 litre saf suda 100 gr hibiskus çiçeği kurusu eklenerek içine sirke ve şap katılıp 2'şer saat kaynatılmıştır. 


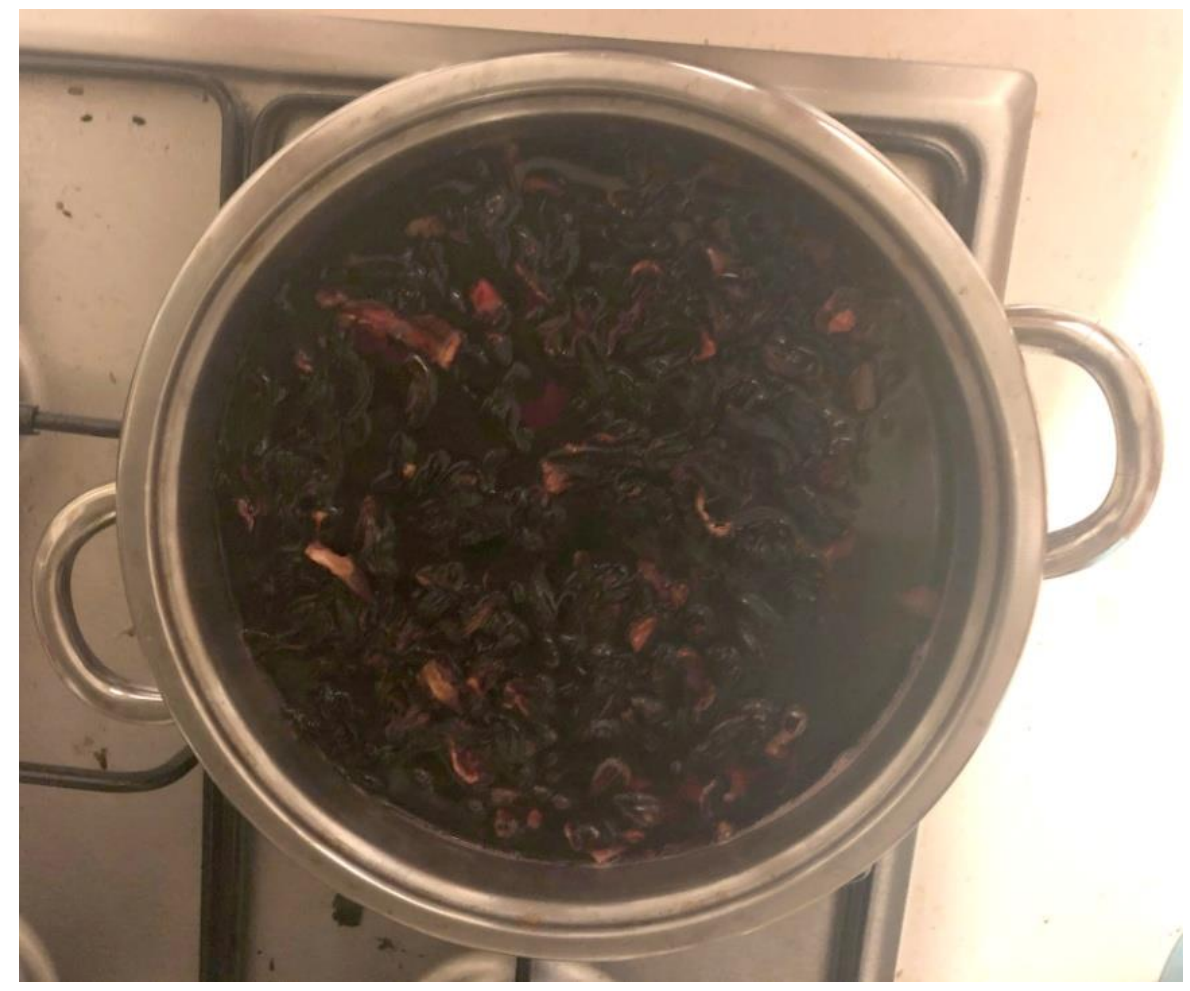

Görüntü 2: Hibiskus ile tekstil yüzeylerinin kaynatılması

Aşağıda solda gösterilmekte olan bezayağı dokuma beyaz pamuklu kumaş hibiskus ile boyanarak sağdaki görüntü elde edilmiştir. Pamuklu kumaşın, polyester içerikli tekstil yüzeyine nazaran daha iyi renklendiği sonucuna varılmıştır.

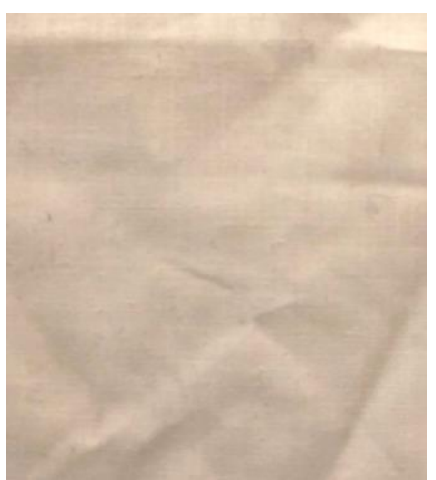

Görüntü 3: Beyaz renkli pamuklu kumaş

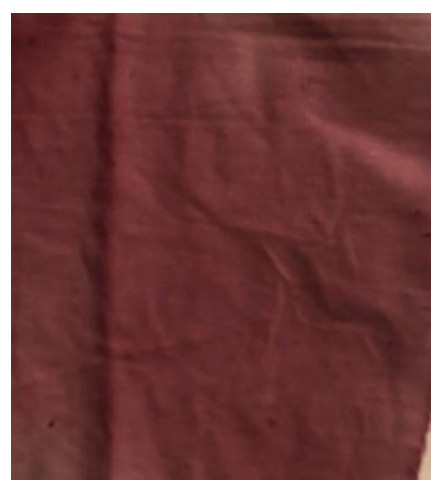

Görüntü 4: Hibiskus ile kaynatılmış pamuklu kumaş

Aşağıda solda yer alan (Görüntü 5) polyester beyaz kumaş hibiskus ile kaynatılarak sağdaki (Görüntü 6) sonuç elde edilmiştir. $\mathrm{Bu}$ bağlamda polyester içerikli kumaşın doğar boyar maddeyi homojen şekilde emmediği gözlemlenmiştir. Ayrıca ortaya çıkan renk yoğunluğu da azdır.

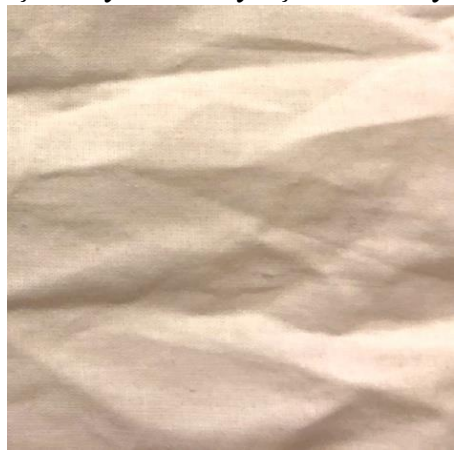

Görüntü 5: Beyaz renkli polyester kumaş

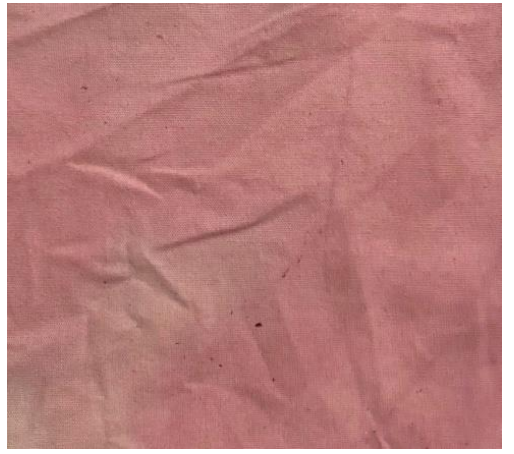

Görüntü 6: Hibiskus ile kaynatılmış polyester kumaş 
Aşağıda (Görüntü 7-8) pamuk polyester karışımlı kumaşın hibiskus ile renklendirilmesi sonucu ne \%100 pamuklu kumaş kadar iyi renklendiği ne de \%100 polyester kumaş kadar heterojen bir pigmentasyona meyilli olduğu görülmektedir. İyi derecede renk çıtısı elde edildiğini söylemek mümkündür.

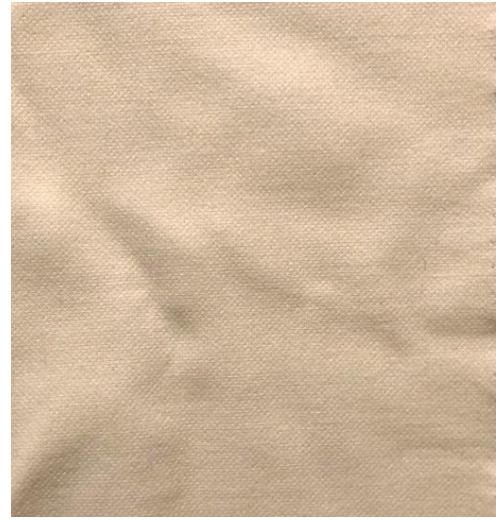

Görüntü 7: Beyaz renkli pamuk polyester karışımlı kumaş

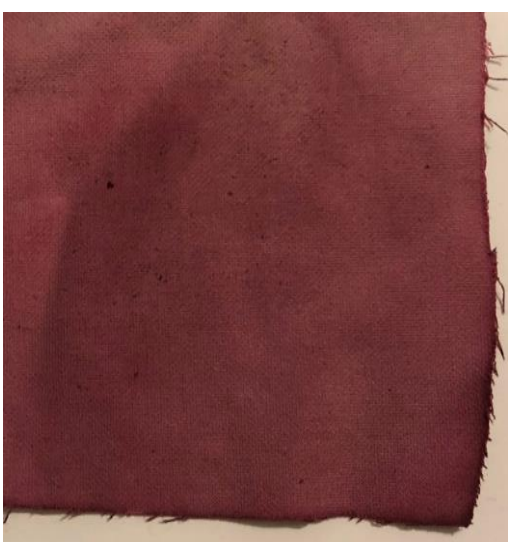

Görüntü 8: Hibiskus ile kaynatılmış pamuk polyester karışımlı kumaş

Aşağıda (Görüntü 9) dimi dokuma \%99 pamuk, \%1 elastan içerikli beyaz renk kot kumaşı hibiskus ile kaynatılarak renklendirilmiştir. Sonuç olarak rengin daha homojen emildiği ve rengin daha koyu göründüğü gözlemlenmektedir. Bez ayağı dokuma pamuklu kumaşa göre renk pigmentasyonunun daha iyi sonuçlanmasını sebebi olarak dokuma çeşidi farklılıklarının boyar maddeyi tutuculuğunu etkilediğini söylemek mümkündür.

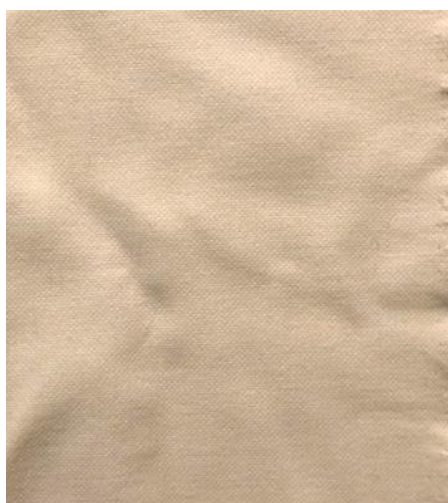

Görüntü 9: Beyaz renkli kot kumaşı

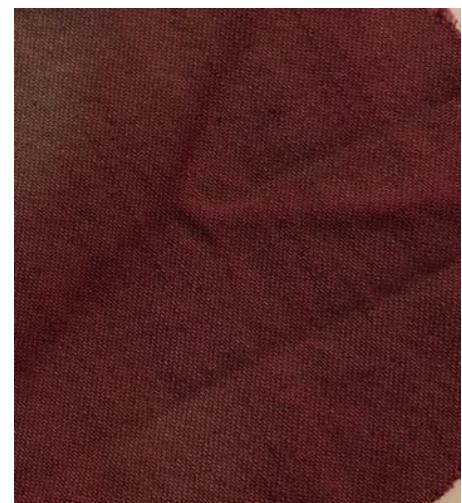

Görüntü 10: Hibiskus ile kaynatılmış kot kumaşı

Sıcaklık, nem ve bazik ortam ile elde keçeleştirilmiş olan doğal rengindeki koyun yünü (Görüntü 11) hibiskus ile kaynatılarak renklendirilmiştir. Sonuç olarak renk iyi bir şekilde emilmiş ve homojen dağılım göstermektedir (Görüntü 12). Yünün kendine has pulcuklu yapısının keçeleşmeye katkı sağladığı gibi renk tutuculukta da önemli bir rolü üstlendiği söylenebilir.

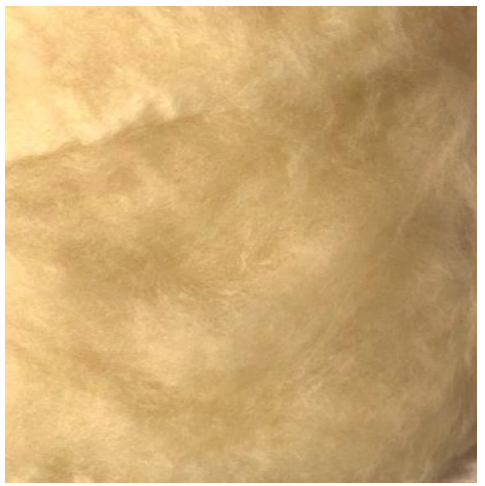

Görüntü 11: Doğal renkli koyun yünü keçeleştirilmiş hali

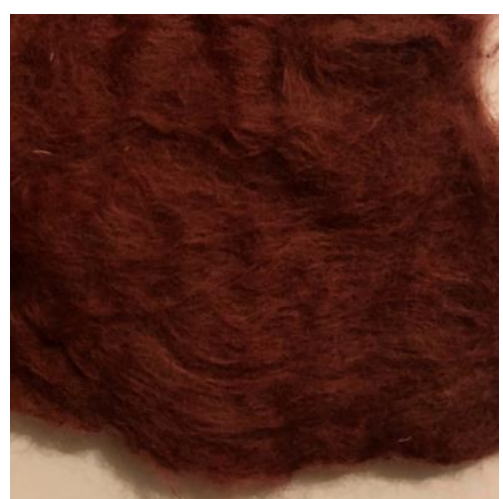

Görüntü 12: Hibiskus ile kaynatılmış keçe 
Açık renk dana derisi (Görüntü 13) hibiskus ile kaynatıldığında sıcaklık dolayısı ile yapısal bozulmalara uğramıştır. Kaynar sudan çıkarıldığında önce kaygan ve oldukça yumuşak bir kıvamda olduğu görülen dana derisi kurumaya bırakıldığında sertleşerek tam anlamıyla katı bir hal almıştır ve kullanıma elverişli yapısını kaybetmiştir. Renk emiciliğine bakıldığında derisinin parlak dış yüzeyi matlaşmıştır (Görüntü 14). Derinin süetimsi iç yüzeyi ise kaynatımdan hemen sonraki aşamada daha kaygan ve parlak bir görünüme sahip olmuştur (Görüntü 15). Dana derisinin renk absorbe yeteneğine bakıldığında iç kısmının hibiskus pigmentlerini tam anlamıyla emerek oldukça koyu bir renge sahip olduğu gözlemlenmektedir.

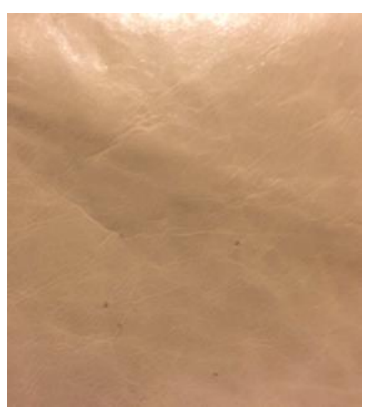

Görüntü 13: Dana derisi

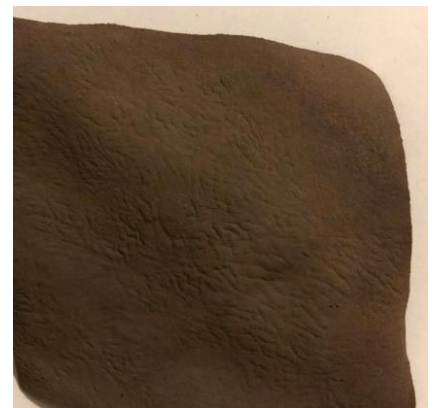

Görüntü 14: Dana derisi dış yüzeyi

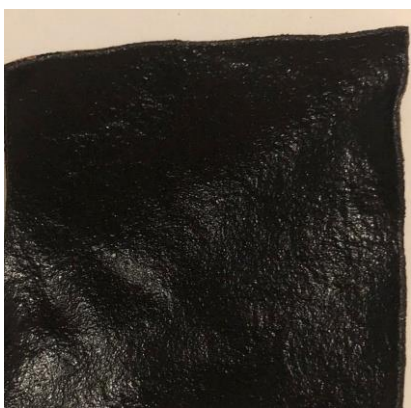

Görüntü 15: Dana derisi iç yüzeyi

Aşağıda (Görüntü 16) beyaz renk koyun derisi görülmektedir. Koyun derisi de kaynatıldığında yapısal bozulmaya uğrayarak dana derisinin boyama sonuçlarıyla benzer çıktılar göstermiştir. Renk emiciliğine bakıldığında derisinin parlak dış yüzeyi matlaşmıştır (Görüntü 17). Derinin süetimsi iç yüzeyi ise kaynatımdan hemen sonraki aşamada daha kaygan ve parlak bir görünüme sahip olmuştur (Görüntü 18). Koyun derisinin renk absorbe yeteneğine bakıldığında iç kısmının hibiskus pigmentlerini tam anlamıyla emerek oldukça koyu bir renge sahip olduğu gözlemlenmektedir.

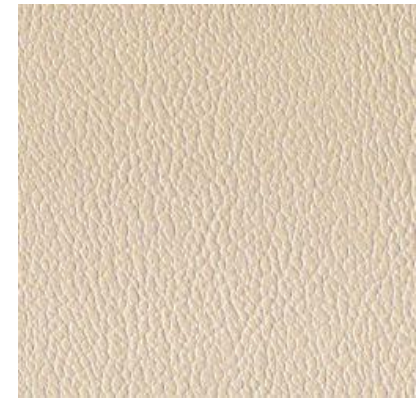

Görüntü 16: Beyaz koyun derisi

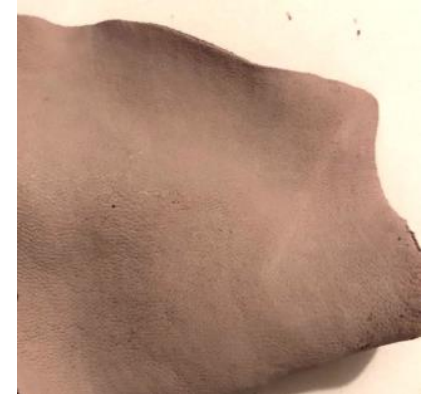

Görüntü 17: Koyun derisi dış yüzey

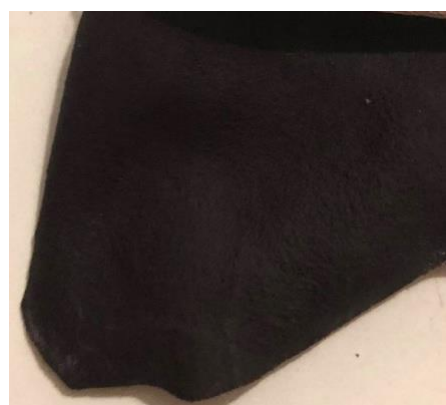

Görüntü 18: Koyun derisi iç yüzey

\section{Bulgular}

Deneyimlenen çalışma 1şığında, doğal boyar maddelerin çeşitli tekstil lifleri ve yüzeyleri üzerinde birbirinde farklı sonuçlar doğurduğu gözlemlenmiştir. Pamuklu kumaşın polyester kumaşa göre boya emiciliğinin daha yoğun ve homojen olduğu söylenebilir. Ayrıca çalışma kapsamında boyaması deneyimlenen farklı dokuma çeşitlerinde kumaşların boyama sonuçlarının farklılık gösterdiği görülmektedir. Söz gelimi dimi dokuma, bez ayağı dokumaya göre daha iyi sonuçlar vermektedir. Öte yandan yün lifinin pulcuklu yapısı sayesinde renk tutuculuğu açısından başarı gösterdiği gözlemlenmektedir. Deri yüzeyler ise her ne kadar boyama açısından iyi sonuçlar vermiş olsa da, sıcaklığın etkisiyle sahip olduğu yapısal özellikleri kaybederek kullanıma elverişli halini yitirmiştir. Bu bağlamda çalışma kapsamında boyar madde, yardımcı maddeler ve sıcaklık göz önünde bulundurulduğunda deri yüzeyi için olumsuz sonuçlar doğurmuştur.

\section{Tartışma, Sonuç Ve Öneriler}

Boyama alanlarında, endüstriyel olarak 10.000 'den fazla farklı boya ve pigmentin kullanıldığı tahmin edilmektedir ve dünya çapında yılda 7 x 105 ton sentetik boya üretilmektedir (Ogugbue, Sawidis, 2011 s.11). Buna bağlı olarak fabrika atıkları da bir hayli fazladır ve çevreye oldukça büyük zararlar verebilmektedir. Özellikle temiz su kaynakları büyük zararlar görmektedir. Son yıllarda insan sağlığı ve çevre kirliliği alanlarındaki bilinçlenme sayesinde bazı değişimler ortaya çıkarak insanlar bu konulara karşı daha duyarlı hale gelmişlerdir. Bu nedenle 
çevre dostu ve insan sağlığı üzerine toksik etkileri olmayan ürünlere yönelik ilginin daha da artmakta olduğu gözlenmektedir.

Hazır giyim sanayisinin doğa düşmanı olarak görülmeye başlanması ile günümüzde çeşitli önlemler alma yolunda çevre örgütlerinin girişimleri olmaktadır. Özellikle kumaş ve deri boyama fabrikaları oldukça fazla temiz su kullandığı, çevreye kimyasal yüklü atıklar saldığı için küresel 1sınmayı ve canlıların neslinin yok oluşunu tetiklemektedir. Çalışmanın amacı doğal boyamayı desteklemek ve farklı tekstil yüzeylerinde meydana getirdiği sonuçları incelemektir. Çalışma kapsamında boyar madde, yardımcı maddeler ve sıcaklık göz önünde bulundurulduğunda deri yüzeyi için olumsuz sonuçlar doğurmuştur. Tabi ki farklı yöntemler kullanılarak deri yüzeyler içinde uygun doğal boyama yöntemleri olabilir. Elde edilen sonuçlar bu çalışmaya ve bu çalışmada kullanılan boyar madde ile yardımcı elemanlara özgüdür. Sıcaklık, mordanlama, boyar madde ve tekstil yüzeyleri çeşitlendirildiğinde farklı sonuçlar elde etmek mümkün olabilir.

$\mathrm{Bu}$ bağlamda üretici fabrikalar ve tüketiciler üzerine düşen görevleri yerine getirerek insana ve doğaya verilen zararı minimize etmek zorundadır. Bu konu ile ilgili kimi devletlerin cezai yaptırımları olsa da sayıları oldukça düşüktür. Kişilerin bilinçlendirilmesi ve devlet tarafindan çeşitli teşviklerde bulunulması gerekmektedir. Tüketicilerin de insana ve doğaya zara veren tüm bu süreçlerden haberdar edilerek, doğal boyaların kullanıldığ tekstil ürünlerini tercih etmeleri konusunda bilinçlendirilmesi sorunları çözmede rol oynayabilir.

\section{Kaynakça}

Bechtold, T; Mussak, R,2009. Historical Aspect, Handbook of Natural Colorants, Wiley, Belçika, :3-17

Benli, H; Yılmaz M; Bahtiyari M. İ, 2012. Geleneksel Türk Ebru Sanatında Doğal Boyarmaddelerin Kullanılabilirliği, Akdeniz Sanat Dergisi, 10: 21-33.

Bhardwaj HC; Jain KK, 1982. Indian Dyes and Industry during 18th-19th century. Indian Journal of History of Science, 17(1): 70-81.

Bilir, M.Z; 2018. Ekolojik Boyama Esaslı Çok Renkli Yüzey Tasarımı, Yedi: Sanat Tasarım ve Bilim Dergisi,20: 63-73.

Gürcüm, B; Yüksel, C. 2014. Moda Sektörünü “Yavaşlatan” Eğilim: Eko Moda ve Moda'da Sürdürülebilirlik, Akdeniz Sanat Dergisi. 4 (8): 48-51.

Hashim, F; Zarkani, A; Al Azzawi, O; Shawkat, M. Fabrics Dying Withhibiscus Sabdariffaand Curcuma Longaextracts Usingdifferent Mordants And Mordanting Methods, Tikrit Journal of Pure Science, 23: 61-69.

Kadolph, S. J; Casselman, K. D. 2004. In The Bag: Contact Natural Dyes. Cloth. Text. Res. J. 22: 15-47.

Karadağ, R. 2007. Doğal Boyamacılık. TC Kültür ve Turizm Bakanlığı, Geleneksel El Sanatları Döner Sermaye İşletmesi Merkez Müdürlüğü, Ankara.

Kırmızı, G. M. 2009. Japon Tekstil Boyama ve Desenlendirme Teknikleri Üzerine Bir Araştırma, Yayımlanmamış Yüksek Lisans Tezi, Dokuz Eylül Üniversitesi, İzmir.

Ogugbue CJ; Sawidis T. Bioremediation and Detoxification of Synthetic Wastewater Containing Triarylmethane Dyes by Aeromonas hydrophila Isolated from Industrial Effluent. Biotechnology Research International 2011, 10-19.

Oyman, N. R; Can, D. İ. 2017. Okaliptüs Bitkisiyle İpek vePamuklu Kumaş Üzerine Eko- Baskı Uygulamaları, II. Uluslararası Akdeniz'de Sanat Sempozyumu, 189-194.

Shahid, M; Shahid-ul-Islam; Mohammad, F. 2013. Recent Advancements In Natural Dye Applications: A Revie, Journal of Cleaner Production, 53, 310-311.

Shahid-ul-Islam; Mohammad F. 2017. Ecological dyeing of wool with biomordants. Sustainable Fibres and Textiles The Textile Institute Book Series, 117-133.

Shanker, R; Vankar, P, 2007. Dyeing cotton, wool and silk with Hibiscus mutabilis (Gulzuba), Dyes and Pigments: 74, 464-469.

Yıldırım, L; İşmal, Ö. E. 2017. Tasarıma Ekolojik Bir Yaklaşım: Atık Biyomateryalle Renklendirilmiş Çocuk Giysileri, II. Uluslararası Akdeniz'de Sanat Sempozyumu, 132-136.

http://www.tcfdatu.org/tr/servisler/servisler/dogal-boyama-31.htm 


\section{EXTENDED ABSTRACT}

When we look at the history of humanity, we cannot predict the emergence of art as well as the beginning of the history of painting. Natural dyes were obtained from various plants, animals and minerals over the years. Natural colouring agents; It can be said that it is a part of human life and art from the wall paintings on hunting scenes, which are found in the shelter buildings of the Polished Stone Age, to the colour of wool, mohair, cotton and silk which are the raw materials of their fabrics. The first evidence of textile dyeing in the BC BC excavations. It is based on the discovery of a piece of cotton dyed with vegetable pigment from 3000 years (Bhardwaj; Jain, 1982, p.70). One of the oldest known dyestuffs is indigo. Indigo dyestuff may be presumed to be India where it was first used in $3200 \mathrm{BC}$ because it was located in an archaeological site which was then within the borders of India (Montenegro, 2007, p.8). Natural dyestuffs of various colours can be obtained from some plants, insects and shellfishes. The use of root, stem, leaves, flowers and fruits of plants as dyestuff and pigment is as old as human history. The use of dye plants in BC. It is said that he went until 4000 years. However, following the industrialization, the use of synthetic dyestuffs and the use of dye plants have been reduced to the point of disappearance. In the 1980s, with the determination that many of the synthetic dyestuffs are toxic, carcinogenic and cause environmental pollution, natural dyeing has gained importance again. As a result, the concept of sustainability has entered our lives. In this study; In the light of an environmentalist thought structure, the effects of plant dyeing methods on the surfaces formed with different textile fibres and their results were evaluated. A flower with red tones of pomegranate, known as pomegranate flower, Mecca rose, hatmi flower or hibiscus (hibiscus) was used as a dyestuff. In the structure of the structure of the Hibiscus dyed materials are available. Mordents; It is a material such as alum, soda, sodium sulphate, sodium carbonate, copper sulphate, aluminium sulphate, which increases the absorbability of the fibres and enables the dye to adhere on the fibres. They also affect the shades of paints. Solvents; dyes, substances are melted inside. Especially for water-soluble paints, water must be free of lime and iron. Acid, base and salts are used as auxiliary substances to make the paint bright and durable (Red, 2009, p.28). In this study, the coloration of seven different textile surfaces with hibiscus plant was investigated. These textile surfaces are all white or pure colour; a cloth fabric consisting of a piece of cloth and a twill weave, a polyester fabric, a polyester-cotton blended twill weave, the surface of a sheep's wool formed by felting and sheep and calf leather, two leather surfaces were used. In addition, each textile surface has to be separately; Add $100 \mathrm{~g}$ of hibiscus blossom in 1 litter of pure water and add vinegar and alum and boil for 2 hours each. In the light of experience, it has been observed that natural dyestuffs have different results on various textile fibres and surfaces. It can be said that cotton fabric is more dense and homogenous than polyester fabric. In addition, it is seen that the dyeing results of the fabrics differ in the different weaving types experienced during the painting. For example, twill weaving gives better results than weaving. On the other hand, it is observed that wool fibre has success in colour retention due to its flake structure. Although the leather surfaces gave good results in terms of dyeing, they lost their structural properties due to the effect of temperature and lost their use. In this context, in the scope of the study, dyestuffs, auxiliary substances and the surface of the skin has negative consequences for the surface. 